\title{
Impact of progressive urbanization and changing cropping systems on soil erosion and net primary production
}

\author{
Qingshui Lu*, Zhiqiang Gao, Jicai Ning, Xiaoli Bi, Qiuxian Wang \\ Yantai Institute of Coastal Zone Research, Chinese Academy of Sciences, Yantai 264003, China
}

\section{A R T I C L E I N F O}

\section{Article history:}

Received 19 June 2014

Received in revised form 6 November 2014

Accepted 28 November 2014

Available online 9 December 2014

\section{Keywords:}

Cropping system

NPP

Shandong Peninsula

Soil erosion

Urbanization

\begin{abstract}
A B S T R A C T
As soil erosion has become a serious threat to agriculture in China, the "Grain-for-Green" project was initiated in western and central China with the goal of reducing soil erosion and improving vegetation conditions. Eastern China was not included in this project, although soil erosion is a serious problem in areas with rapid urban expansion. This study analysed the effects of urbanization on cropping system changes, soil erosion, and farmland net primary production (NPP) in Shandong Peninsula using the Revised Universal Soil Loss Equation (RUSLE) model and Carnegie Ames Stanford Approach (CASA). The results show that parts of the mountainous regions in eastern Shandong Peninsula experience severe/ heavy soil erosion. The percentage of cropland experiencing high, very high, and severe soil erosion decreased by 46.1\%, 60.3\%, and 33.3\%, respectively, from 2000 to 2010. Although the mean annual unit NPP increased by $10.8 \%$ because of changes in climate, species, and management, the total NPP of cropland still dropped slightly on the Shandong Peninsula due to urbanization, and the area of singlecropping systems on lands that suffer higher soil erosion rates decreased. However, this declining area in lands with higher soil erosion classes will help to reduce the soil erosion rate on the Shandong Peninsula, which indicates that implementing the "Grain-for-Green" project in this area is not necessary in the foreseeable future.
\end{abstract}

(c) 2014 Elsevier B.V. All rights reserved.

\section{Introduction}

Soil erosion has become a serious environmental threat in China, and enormous amounts of sediment are transported from land to the sea through river channels every year. About $6.8 \times 10^{8} \mathrm{t}$ of sediment is transported to the Yellow River from sediment-rich regions in the Yellow River catchment annually (Jiao et al., 2014). Annually, 337 million tons (Mt) of sediment reached the sea from the Yangtze River catchment during 1993-2006 (Dai and Lu, 2014). This huge amount of sediment flux normally deposits in river channels, lakes, and reservoirs, which greatly decreases the flood storage capacity (Pu et al., 1994; Yang et al., 2003; Liu et al., 2007; Yue et al., 2014). Moreover, soil loss caused by erosion reduces soil fertility and grain production (Bechmann et al., 2009; Quinton et al., 2010; Su et al., 2010; Otero et al., 2011).

The Grain-for-Green project was launched in 1999 to increase forest cover and combat soil erosion on sloping cropland (Qi et al., 2013; Wu et al., 2014). In practice, governments designate a certain

\footnotetext{
* Corresponding author. Tel.: +86535 2109256.

E-mail address: qslu@yic.ac.cn (Q. Lu).
}

quota of cropland in each province of western China every year, and farmers who agree to stop cultivating these lands would receive subsidies to cover their loss. However, no quota is established to stop cultivating cropland in eastern China, and it is a farmer's own decision if the cropland that suffers soil erosion should be converted to forest or grassland.

Meanwhile, China has also experienced rapid urbanization. The urban area in the eastern coastal provinces increased from 909,721 ha in 1990 to $3,294,289$ ha in 2010 , a $262.1 \%$ increase according to remote sensing image interpretation. The urban population had reached 669 million, and the gross domestic production (GDP) had increased to 40,326 billion Chinese yuan by the end of 2010 (State Statistical Bureau, 2011). Now China is ranked as the world's second largest economy.

Rapid urbanization has caused changes in cropping systems and other land-use classes. Those changes in farmlands would further affect the soil erosion rate and agricultural production in eastern China. However, no studies have analysed the relationships among urbanization, soil erosion, cropping systems, and agricultural production. The Shandong Peninsula is an area in eastern China that suffers extensive soil erosion and rapid urbanization, and was therefore selected for our study. Our objectives were to analyze the 
spatial pattern of soil erosion, the dynamics of farmlands and cropping systems in each soil erosion class, and possible responses to soil erosion and diminished agricultural production.

\section{Study area}

The study area is located at $35^{\circ} 0^{\prime} 33^{\prime \prime}-38^{\circ} 0^{\prime} 44^{\prime \prime} \mathrm{N}, 119^{\circ} 32^{\prime} 5^{\prime \prime}-$ $122^{\circ} 43^{\prime} 9^{\prime \prime} \mathrm{E}$, within Shandong Province, eastern China (Fig. 1 ). The peninsula is composed of 14 counties and 3 cities, with a total land area of $29,411.7 \mathrm{~km}^{2}$. Elevations range from 0 to $1130 \mathrm{~m}$ above sea level, and most agricultural lands are found in lowland areas with elevations of less than $500 \mathrm{~m}$. Climate in the Shandong Peninsula belongs to the Asian monsoon system. Summer is warm and wet, whereas winter is cold and dry. Monthly mean maximum air temperature in summer is $25^{\circ} \mathrm{C}$, while the monthly mean minimum air temperature in winter is $0^{\circ} \mathrm{C}$. Annual precipitation ranges from 600 to $700 \mathrm{~mm}$ according to weather observation data in the past five decades. The cropping systems in our study area consist of double-cropping and single-cropping systems. The double-cropping system consists of winter wheat and summer corn, whereas the single-cropping system mainly involves peanuts. Other major land-use/land-cover categories in the study area include woodland (mainly deciduous trees), water, and barren land.

\section{Data and methodology}

\subsection{Data and preparation}

Three main datasets were used to analyse the relationships among soil erosion, cropping system changes, and agricultural production. The first, spatial data of cropping systems and other land-use categories on the Shandong Peninsula in 2000 and 2010, was derived from remote sensing images. Landsat Thematic Mapper (TM) images in early May, September, and late October for the years 1999-2001 were used to identify cropping systems and other land-use categories in 2000. Those images were acquired from the U.S. Geological Survey (USGS; www.usgs.gov). Huan Jing 1A (HJ1A) and Huan Jing 1B (HJ1B) images in early May, September, and late October for the years 2010-2012 were used to extract the cropping systems and other land-use categories in 2010. Those images were downloaded from the China Center for Resources Satellite Data and Application (www.cresda.com).

The second dataset, the soil erosion modeling output, was calculated using the Revised Universal Soil Loss Equation (RUSLE). The data used for the input of the RUSLE model in our study area were daily rainfall, the land-use/land-cover map, the digital elevation model (DEM), the 1:1,000,000 map of Chinese soils, and the normalized difference vegetation index (NDVI). The daily rainfall data from 1980 to 2000 were obtained from the 107 weather observation stations in Shandong, Jiangsu, Hebei, Beijing, and Liaoning provinces recorded by the State Meteorological Bureau. Land-use/land-cover and Chinese soils data were downloaded from the Data Center of the Chinese Academy of Sciences (http://www.resdc.cn). The 30-m posting DEM for our study area was acquired from the USGS. Spot NDVI data for the year 2000 was downloaded from the SPOT-Vegetation Program (www.spot_vegetation.com).

The third dataset, the net primary production (NPP) modeling output, was calculated from the Carnegie Ames Stanford Approach (CASA) model (Potter et al., 1993; Field et al., 1995). For this area, the data input into the CASA model were the daily maximum and minimum temperatures, actual vapor pressure, actual sunshine duration, daily precipitation, wind velocity, Moderate Resolution Imaging Spectroradiometer (MODIS) MCD43A3 (albedo), and MODIS fraction of photosynthetically active radiation (FPAR). The MODIS data were downloaded from the USGS (www.usgs.gov), and meteorological data were obtained from the 107 weather observation stations in northern China and recorded by the State Meteorological Bureau.

\subsection{Classification of cropping systems and other land-use categories}

The spectral signature of land use/land cover is mainly dependent upon the vegetation type and its growing condition when the image was acquired. Generally, four growing stages of the double-cropping system can be identified in our study area. The first period from late October to next late June is the time when the winter wheat is growing. After winter wheat is harvested, the land is left fallow from late June into early July. The summer corn starts growing from early July and would be ready for harvest by late October. Another short fallow period stretches from late

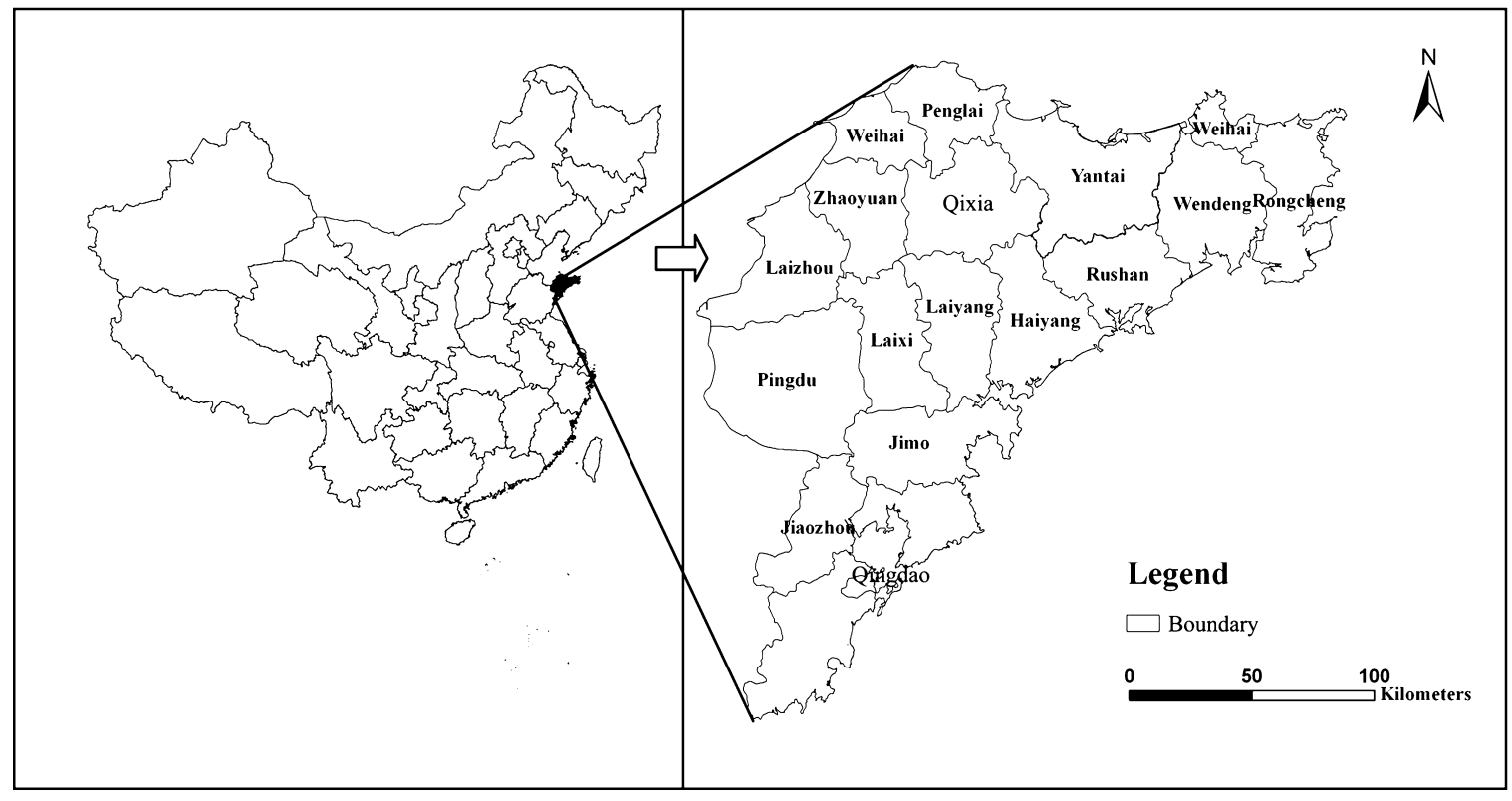

Fig. 1. Location of Shandong Peninsula. 
October to early November right after the corn is harvested. In contrast, for the single-cropping system (mainly peanuts), the growing period normally lasts from early May to late October, and the land would be left fallow after peanut harvest until next May. Forest in our study area starts to grow from late March and leaves start to fall in late November. Given their special spectral signatures, barren lands and water bodies could be easily delineated from the Landsat and HJ1A images during the period from early July to late September when trees and crops are growing.

To better capture the variations in spectral signatures of different land-use/land-cover categories in our study area, multitemporal Landsat and $\mathrm{HJ} 1 \mathrm{~A}$ images were obtained. One image acquired during late October to early November was used to distinguish the croplands from other land-use/land-cover categories. The second image acquired in early March to early May in the next year was used to identify the single-cropping lands (which are left fallow during this period) from double-cropping lands with growing crops at this time. Another image acquired in late May to late September was also used to better identify the two types of cropping system. In total, 24 images were acquired for the periods 1999-2002 and 2010-2012 in this study. The Landsat images were used to extract land-use/land-cover categories for 2000 and HJ1A images for 2010.

Five land-use/land-cover categories were automatically classified from the remote sensing images, including forest and orchard, double-cropping land, single-cropping land, no-vegetable land, and water. The three-date NDVI images within each crop calendar year were stacked together and then classified by using a supervised maximum likelihood classifier. Training sites were first delineated from the natural-color composite of the original Landsat images and then transferred to the NDVI composite. For details, refer to Lu et al. (2011).

We randomly selected 144 points for each individual category and read their land-use/land-cover types from the map in 2000. Then, the results were compared to ground truth data collected in field surveys and visual interpretation of China \& Brazil Earth Resource Satellite (CBERS) images and other high-spatial-resolution images in Google Earth. The overall classification accuracy is over $85 \%$ (Table 1). The area of double-cropping systems in 2010 was compared with that from statistical yearbooks; the Pearson correlation coefficient was above 9.0 (Local Statistic Bureau, 2010).

\subsection{Soil erosion}

Soil erosion in our study area was estimated with the Revised Universal Soil Loss Equation (RUSLE), which relates the rate of soil loss in tons per acre per year $(A)$ to the erosive power of the rain $(R)$, the soil erodibility $(K)$, the land slope and length (LS), the degree of soil cover $(C)$, and conservation practices $(P)$, as in Eq. (1).

$A=R \times K \times \mathrm{LS} \times C \times P$

The RUSLE was developed by McCool et al. (1987) by incorporating new results of research, experiments, and data into its predecessor, the Universal Soil Loss Equation (USLE), which was published by Wischmeier and Smith (1978). In this study, an individual raster was prepared for each of the above five factors. $R$ per year was calculated for each weather observation station, and then interpolation was used to obtain the raster data for $R$. The average soil particle size was calculated from the 1:1,000,000 Chinese soil vector data and then converted into raster data with interpolation. LS were obtained from the ASTER DEM data from the National Aeronautics and Space Administration (NASA). $C$ values were calculated from NDVI raster data. $P$-values were assigned for different land use/land cover categories, as recommended by Wischmeier and Smith (1978), Renard et al. (1997), and Xu et al. (2011).

The sections that follow describe the data and parameters used to calculate these factors based on recent research in the study area.

\subsubsection{Erosive power of the rain ( $\mathrm{R})$}

The factor $R$ represents the erosion potential of rainfall-runoff, which is directly related to erosion yield. This study used the equation developed by Zhang et al. (2002) to calculate $R$ (Eq. (2)):

$R=\alpha \sum_{j=1}^{k}\left(P_{j}\right)^{\beta}$,

where $R$ is the half month rainfall erosivity factor in $m m h^{-1} h^{-1}$ year $^{-1}, k$ is the total number of days in the corresponding half month, $P_{j}$ is the erosive rainfall in $\mathrm{mm}$ for day $j$, and $\alpha$ and $\beta$ are model parameters.

The daily rainfall data for the period from 1980 to 2000 in each month were divided into two sections based on the fifteenth day of the month to give 24 sections for 1 year. For a specific section, the total number of days $(k)$ was calculated first. For the $j$ th day in this section, $P_{j}$ was the total rainfall if it exceeded $12 \mathrm{~mm}$ (Xie et al., 2000). Otherwise, $P_{j}=0$ and was not considered in the calculation. Model parameters $\alpha$ and $\beta$ were calculated according to Eq. (3):

$\beta=0.8363+\frac{18.144}{P_{d 12}}+\frac{24.455}{P_{y 12}}$,

$\alpha=21.586 \beta^{-7.1891}$,

where $P_{d 12}$ and $P_{y 12}$ are the average daily and annual rainfall in $\mathrm{mm}$, respectively, for the days with a total rainfall exceeding $12 \mathrm{~mm}$. The final $R$ values were calculated for each of the weather observation stations, and a map of the $R$ values was prepared for our study area using the spline interpolation method in ArcGIS.

\subsubsection{Soil erodibility factor $(K)$}

This factor mainly measures the influence of soil texture and other soil characteristics on soil loss. It was calculated using Eq. (4):

$$
\begin{aligned}
K & =7.954 \\
& \times\left\{0.0017+0.0494 \times \exp \left[-\frac{1}{2}\left(\frac{\log \left(D_{g}\right)+1.675}{0.6986}\right)^{2}\right]\right\},
\end{aligned}
$$

where $D_{g}$ represents the average soil particle size ( $\mathrm{mm}$ ), which was acquired from the 1:1,000,000 Chinese Soil Database.

\subsubsection{Length-slope factor (LS)}

The LS factor reflects the topographic influence on soil erosion, as soil loss tends to increase as the slope increases and lengthens. The slope steepness and slope length were first calculated from the Advanced Spaceborne Thermal Emission and Reflection

Table 1

\begin{tabular}{|c|c|c|c|c|c|c|}
\hline Type & Year & Double cropping system (\%) & Single-cropping system (\%) & Orchard and forest (\%) & Water (\%) & Bare and residential land (\%) \\
\hline User's accuracy & 2000 & 96.4 & 85.8 & 99.2 & 97.2 & 88.8 \\
\hline Producer's accuracy & 2000 & 93.1 & 88.1 & 92.9 & 96.5 & 98.6 \\
\hline
\end{tabular}

Image classification results in 2000. 
Radiometer (ASTER) DEM data from NASA. Then, the LS factor was computed with Eq. (5) or (6) as proposed by Remortel et al. (2001) for different scenarios.

If the slope $(\theta)$ is less than $5^{\circ}$, Eq. (5) is adopted.

$\mathrm{LS}=\left(\frac{\lambda}{22.13}\right)^{m}(10.8 \sin \theta+0.03)$

If $\theta$ is not less than $5^{\circ}$, Eq. (6) is used:

$\mathrm{LS}=\left(\frac{\lambda}{22.13}\right)^{m}(16.8 \sin \theta-0.96)$,

where $\lambda$ is the slope length and $m$ is the slope exponent. Refer to Remortel et al. (2001) for detailed values of $m$.

\subsubsection{Cover and management factor (C)}

The amount of soil erosion is also affected by vegetation cover and different methods of crop management. In this study, the factor $C$ was derived using Eq. (7) (Liu et al., 2010):

$C=C_{\mathrm{c}} \times C_{\mathrm{s}}$,

where $C_{\mathrm{c}}$ and $C_{\mathrm{s}}$ are the canopy and surface cover factors, respectively. For cropland and grassland, $C_{c}$ was calculated as follows (Eq. (8)).

$C_{\mathrm{c}}=1-\left(0.01 V_{\mathrm{c}}+0.0859\right) e^{-0.0033 h}$

For forestry, $C_{c}$ was calculated with Eq. (9).

$C_{\mathrm{c}}=0.5262 \times e^{-0.05 V_{\mathrm{c}}}$

The factor $C_{\mathrm{s}}$ was computed using Eq. (10):

$C_{\mathrm{s}}=1.029 e^{-0.0235 V_{\mathrm{c}}}$,

where $V_{c}$ is the vegetation coverage percentage (\%) and $h$ is the canopy height $(\mathrm{cm}) . V_{c}$ was obtained from Eq. (11) (Zhang and Duan, 2009):

$V_{\mathrm{c}}=\frac{\mathrm{NDVI}-\mathrm{NDVI}_{\min }}{\mathrm{NDVI}_{\max }-\mathrm{NDVI}_{\min }}$,

where NDVI is the NDVI for a specific land-use/land-cover patch, and $\mathrm{NDVI}_{\text {min }}$ and $\mathrm{NDVI}_{\max }$ are the minimum and maximum NDVI values, respectively, for the same patch.

The final rate of soil loss was then calculated with the spatial analysis functions in ArcGIS (ESRI, Redlands, CA, USA). This method was published by Lu et al. (2013).

Soil erosion was calculated in the Bohai Rim of China to estimate the accuracy of predicted soil erosion. Shandong Peninsula was clipped from the whole region (Fig. 2). The predicted results were compared with the results with ${ }^{137} \mathrm{Cs}$ techniques in Beishicheng, Miyun County, Beijing. Our predicted result in Beishicheng is $20.5 \mathrm{tha}^{-1}$ year $^{-1}$ and fits well with results with ${ }^{137}$ Cs techniques 21 tha $^{-1}$ year $^{-1}$ (Hua et al., 2006).

\subsection{NPP calculation}

The Carnegie Ames Stanford Approach (CASA) model and FAO Penman-Monteith equation on net solar radiation were used to calculate NPP on the Shandong Peninsula (Potter et al., 1993; Field et al., 1995; Folland et al., 2001). NPP is expressed by the following equations:

$\mathrm{NPP}=\mathrm{APAR} \times \varepsilon$

$\mathrm{APAR}=R_{\mathrm{n}} \times \mathrm{FPAR}$

$R_{\mathrm{n}}=R_{\mathrm{ns}}-R_{\mathrm{nl}}$

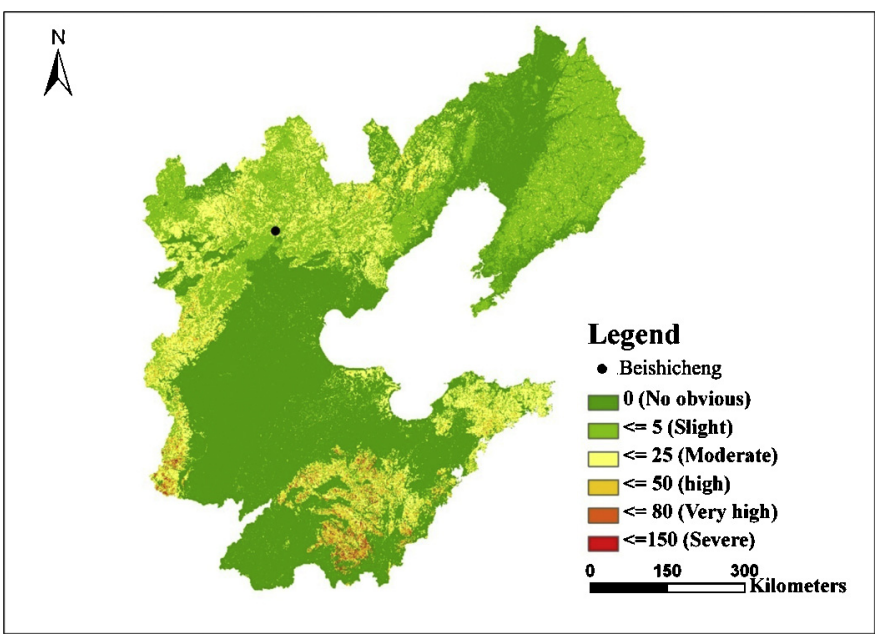

Fig. 2. Predicted soil erosion in Bohai Rim (tha ${ }^{-1}$ year $\left.^{-1}\right)$.

$R_{\mathrm{ns}}=(1-\alpha) R_{\mathrm{s}}$

$R_{\mathrm{s}}=\left(a_{\mathrm{s}}+b_{\mathrm{s}} \frac{n}{N}\right) R_{a}$

$R_{a}=F_{\left(G_{\mathrm{SC}}, d_{\mathrm{r}}, \delta, \varphi J, L_{m}\right)}$

$R_{\mathrm{nl}}=F_{\left(T_{\max }, T_{\min }, e_{s}, R_{\mathrm{s}}\right)}$

$\varepsilon_{(x, t)}=T_{\varepsilon 1(x, t)} \times T_{\varepsilon 2(x, t)} \times W_{\varepsilon(x, t)} \times \varepsilon^{*}$

in which APAR is the photosynthetically available radiation $\left(\mathrm{MJ} \mathrm{m}^{2}\right), \varepsilon$ is light-use efficiency, $R_{\mathrm{n}}$ is net solar radiation $\left(\mathrm{MJ} \mathrm{m} \mathrm{m}^{2}\right)$, FPAR is the component of photosynthetically active radiation, $R_{\mathrm{ns}}$ is net shortwave radiation $\left(\mathrm{MJ} \mathrm{m}^{-2} \mathrm{day}^{-1}\right), \alpha$ is albedo, $R_{\mathrm{S}}$ is shortwave radiation $\left(\mathrm{MJ} \mathrm{m}^{-2} \mathrm{day}^{-1}\right), n$ is actual duration of sunshine (h), $N$ is the maximum possible duration of sunshine or daylight (h), $a_{s}$ and $b_{s}$ are the fractions of extraterrestrial radiation reaching the Earth on a clear day $(n=N), R_{a}$ is extraterrestrial radiation $\left(\mathrm{MJ} \mathrm{m}^{-2} \mathrm{day}^{-1}\right), G_{\mathrm{sc}}$ is a solar constant $\left(0.082 \mathrm{MJ} \mathrm{m}^{-2} \mathrm{~min}^{-1}\right), d_{\mathrm{r}}$ is the inverse relative distance of EarthSun, $J$ is the number of the day in the year between 1 and 365 or $366, \delta$ is solar declination (rad), $\varphi$ is latitude (rad), $L_{m}$ is longitude (degrees), $T_{\max }$ is the maximum absolute temperature during the 24-h period, $T_{\min }$ is the minimum absolute temperature during the 24-h period, $e_{\mathrm{a}}$ is the actual vapor pressure (KPa), $T_{\varepsilon 1(x, t)}$ and $T_{\varepsilon 2(x, t)}$ are temperature stress indices, $W_{\varepsilon(x, t)}$ is the water stress index calculated according to Potter et al. (1993) and Allen et al. (1998), and $\varepsilon^{*}$ is the maximum energy conversion rate $(0.389 \mathrm{gC} / \mathrm{MJ})$. Our calculated mean annual NPP in 2000 was compared with the corresponding MODIS NPP (MOD17A3) (www.usgs.gov); the accordance was $98.8 \%$ (Table 2 ).

Table 2

Accordance comparison between CASA mean annual NPP and MODIS NPP products.

\begin{tabular}{llll}
\hline & MODIS17A3 $\left(\mathrm{g} / \mathrm{m}^{2}\right)$ & CASA $\left(\mathrm{g} / \mathrm{m}^{2}\right)$ & Accuracy $(\%)$ \\
\hline Mean annual NPP & 475.7 & 469.8 & 98.8 \\
\hline
\end{tabular}




\section{Results and analysis}

\subsection{Soil erosion}

The predicted soil erosion was divided into six classes according to the Standards for Classification and Gradation of Soil Erosion by the Ministry of Water Resources issued in 2008. Fig. 3 shows the final predicted soil erosion rate for the Shandong Peninsula in 2000. Generally speaking, land that is suffering soil erosion is mainly in the eastern part of the Shandong Peninsula. The percentage of land that is exposed to very high and severe soil erosion is very small. Most of the land in this area experiences no obvious, slight, and moderate soil erosion. The land area that falls into no obvious, slight, moderate, high, very high, and severe soil erosion classes are 46,642,1,305,551, 949,225, 196,359, 22,524, and 1074 ha, respectively, and their corresponding percentages are 15.9, 44.4, 32.3, 6.7, and 0.8\% (Tables 3 and 4).

The soil erosion rate tends to increase with the increasing slope of land on the Shandong Peninsula (Tables 3 and 4). The area of the Shandong Peninsula with slopes of $5^{\circ}$ and below is $2,344,298$ ha, or $79.7 \%$ of the total area. Among the lands with slope of $5^{\circ}$ and below, percentages of lands that fall into very high and severe classes are

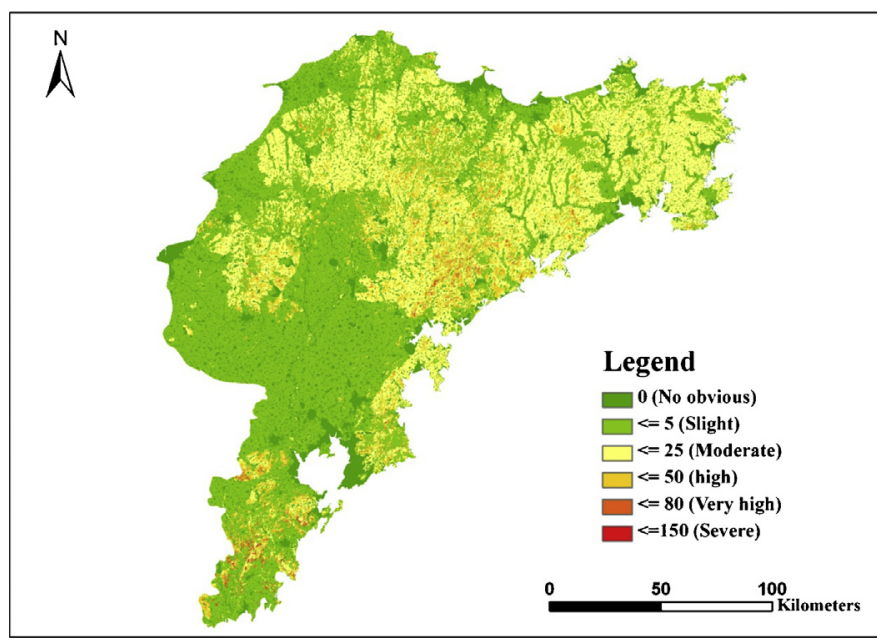

Fig. 3. Predicted soil erosion in Shandong Peninsula ( $\left.t \mathrm{ha}^{-1} \mathrm{year}^{-1}\right)$.
0.3 and $0 \%$, respectively. The area of the Shandong Peninsula with slopes of $15^{\circ}$ and below is 496,075 ha, or $16.9 \%$ of the Shandong Peninsula. Among the lands with slopes of $15^{\circ}$ and below, percentages of lands that fall into very high and severe classes are 15.6 and $0.1 \%$, respectively. The area of lands with slopes of $25^{\circ}$ and below is 90,247 ha, or $3.1 \%$ of the Shandong Peninsula. Among the lands with slopes of $25^{\circ}$ and below, percentages of lands that fall into very high and severe classes are 4.3 and $0.4 \%$, respectively. The area of lands with slopes above $25^{\circ}$ is 10,555 ha, or $0.4 \%$ of the study area. Among the lands with slopes above $25^{\circ}$, percentages of lands that fall into very high and severe classes are 6.3 and $0.9 \%$, respectively.

\subsection{Changes of cropping systems}

The Shandong Peninsula experienced rapid urbanization from 2000 to 2010 (Fig. 4, Tables 5 and 6). Rapid urbanization caused the urban and barren land to rapidly expand from 353,199 ha in 2000 to 556,169 ha in 2010 . The rate of expansion reached $57.5 \%$ between 2000 and 2010 .

Rapid urbanization not only caused the area of double-cropping systems to decrease, but also caused double-cropping systems that fall into various soil erosion classes to change in area from 2000 to 2010 (Tables 5-7). Urban areas that fall into no obvious soil erosion were 165,519 ha in 2000 and increased to 256,989 ha in 2010 by $45.4 \%$. Most of the expanded areas came from single-cropping systems and double-cropping systems. This caused the area of double-cropping system in lands with no obvious soil erosion class to decrease from 59,778 ha in 2000 to 47,164 ha in 2010 , by $21.1 \%$ of the total area of the double-cropping system. At the same time, this also caused single-cropping systems in lands with no obvious soil erosion to decrease from 85,009 ha in 2000 to 60,800 ha in 2010 , a $28.5 \%$ decrease.

Many rural laborers continued to migrate from rural to urban areas from 2000 to 2010. The double-cropping system on sloped land is labor-intensive and suffers a higher soil erosion rate. Decreased labor in rural areas caused the area of the doublecropping system to decrease in the land with higher soil erosion rate (Table 7). The areas of double-cropping system in land that fall into moderate soil erosion, high, very high, and severe soil erosion classes were $144,552,11,123,687$, and 3 ha in 2000 , respectively. Those lands decreased to 83,462, 5997, 273, and 2 ha in 2010, respectively. Corresponding decrease percentages were 42.3, 46.1, 60.3 , and $33.3 \%$.

Table 3

Area of lands that falls into various soil erosion classes in Shandong Peninsula.

\begin{tabular}{|c|c|c|c|c|c|c|c|}
\hline Slope angle (degree) & No obvious (0) (ha) & Slight $(0-5)$ (ha) & Moderate (5-25) (ha) & High $(25-50)$ (ha) & Very high (50-80) (ha) & Severe (80-150) (ha) & Total (ha) \\
\hline$\leq 5$ & 447,034 & $1,094,413$ & 690,521 & 104,651 & 7607 & 72 & $2,344,298$ \\
\hline$\leq 15$ & 18,324 & 159,773 & 229,870 & 77,197 & 10,376 & 535 & 496,075 \\
\hline$\leq 25$ & 977 & 46,247 & 25,741 & 13,035 & 3875 & 372 & 90,247 \\
\hline$>25$ & 107 & 5118 & 3093 & 1476 & 666 & 95 & 10,555 \\
\hline Total & 466,442 & $1,305,551$ & 949,225 & 196,359 & 22,524 & 1074 & $2,941,175$ \\
\hline
\end{tabular}

Soil erosion unit: tha $^{-1}$ year $^{-1}$

Table 4

Percentage of lands that falls into various soil erosion classes in Shandong Peninsula.

\begin{tabular}{|c|c|c|c|c|c|c|c|}
\hline Slope angle (Degree) & No obvious (0) (\%) & Slight $(0-5)(\%)$ & Moderate (5-25) (\%) & High (25-50) (\%) & Very high $(50-80)(\%)$ & Severe $(80-150)(\%)$ & Total (\%) \\
\hline$\leq 5$ & 19.1 & 46.7 & 29.5 & 4.5 & 0.3 & 0.0 & 79.7 \\
\hline$\leq 15$ & 3.7 & 32.2 & 46.3 & 15.6 & 2.1 & 0.1 & 16.9 \\
\hline$\leq 25$ & 1.1 & 51.2 & 28.5 & 14.4 & 4.3 & 0.4 & 3.1 \\
\hline$>25$ & 1.0 & 48.5 & 29.3 & 14.0 & 6.3 & 0.9 & 0.4 \\
\hline Total & 15.9 & 44.4 & 32.3 & 6.7 & 0.8 & 0.0 & 100.0 \\
\hline
\end{tabular}

Soil erosion unit: tha $^{-1}$ year $^{-1}$. 

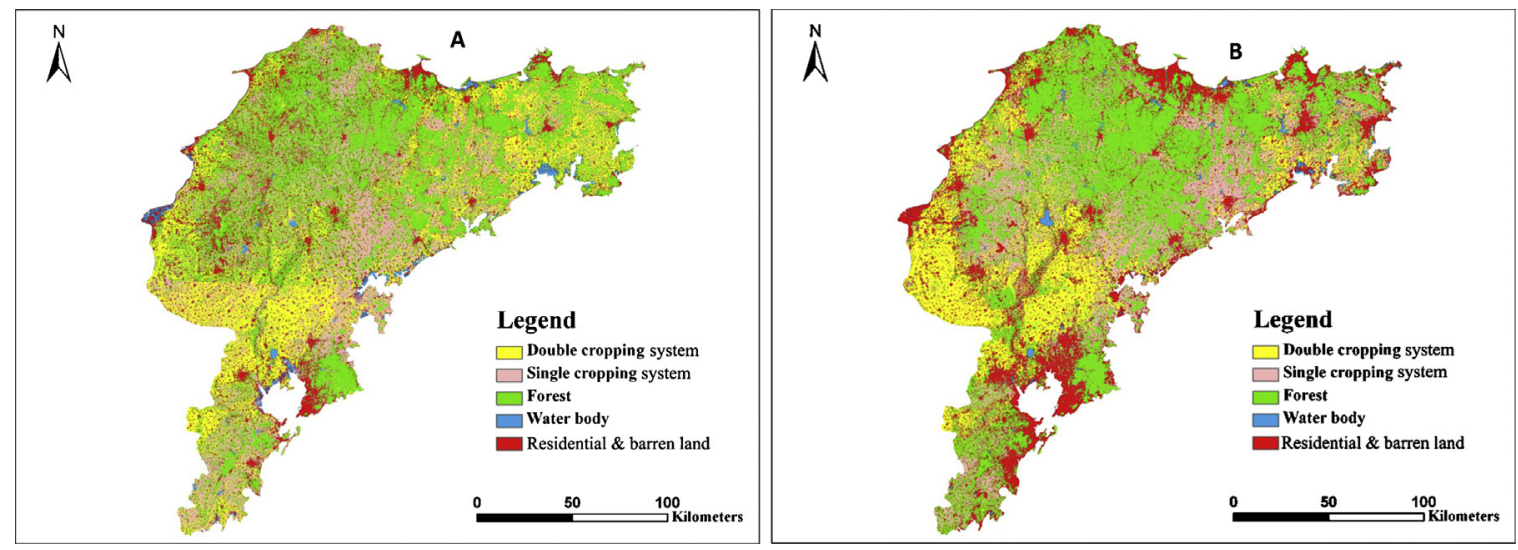

Fig. 4. Cropping systems and other LUCC classes in Shandong Peninsula (A, 2000; B, 2010).

Table 5

Urban areas that fall into various soil erosion classes in the Shandong Peninsula in 2000 and 2010 (ha).

\begin{tabular}{|c|c|c|c|c|c|c|c|}
\hline & No obvious (0) & Slight (0-5) & Moderate (5-25) & High (25-50) & Very high (50-80) & Severe $(80-150)$ & Total \\
\hline 2000 (ha) & 165519 & 94904 & 75724 & 15417 & 1493 & 142 & 353199 \\
\hline 2010 (ha) & 256989 & 180092 & 99935 & 16964 & 2037 & 152 & 556169 \\
\hline Change (\%) & 45.4 & 42.3 & 12.0 & 0.8 & 0.3 & 0.0 & 57.5 \\
\hline
\end{tabular}

Soil erosion unit: tha $^{-1}$ year $^{-1}$.

Decreased rural labor also caused the area of single-cropping systems in lands that suffer higher soil erosion rates to decrease (Table 7). The areas of single-cropping systems in lands that fall into high, very high, and severe soil erosion classes were 75,205 , 8002 , and 215 ha in 2000 , respectively, and correspondingly decreased to 64,662, 6647, and 134 ha in 2010.

Double-cropping systems could provide farmers with more profits than single-cropping systems. Lands with slopes below $5^{\circ}$ could be managed by machinery and were not affected by decreasing rural labor. To make more profit, some of the singlecropping systems in lands with slopes below $5^{\circ}$ that fall into the slight soil-erosion class were converted to the double-cropping system, which caused the area of double-cropping systems to increase and single cropping to decrease. In contrast, some land using a single-cropping system in the moderate soil erosion class with slopes greater than $5^{\circ}$ was converted to a double-cropping system because of decreasing rural labor. This caused the area of

Table 6

Area of cropping systems and other land use classes in Shandong Peninsula.

\begin{tabular}{llllll}
\hline Categories & Double & Single & \multicolumn{1}{l}{ Forest } & Water & Urban \\
\hline 2000 (ha) & 577029 & 781143 & 1194957 & 50596 & 353199 \\
2010 (ha) & 512461 & 710390 & 1277286 & 37147 & 556169 \\
Changes (\%) & -11.2 & -9.1 & 6.9 & -26.6 & 57.5 \\
\hline
\end{tabular}

Note: minus means decrease. the double-cropping systems to decrease and that of the singlecropping systems to increase in lands that fall into the moderate soil-erosion class.

\subsection{Net primary production changes in farmland}

The combined effects of crop species, climate changes, and human management caused the mean annual unit NPP to increase in both cropping systems. It increased more in single-cropping systems than in double-cropping systems (Fig. 5, Table 8). Mean annual unit NPP values in farmlands of double-cropping systems that fall into no obvious, slight, moderate, high, very high, and severe soil erosion classes were 484.4, 488.3, 559.4, 505.2, 502.3, and $492.7 \mathrm{~g} / \mathrm{m}^{2}$ in 2000 , respectively, and correspondingly increased to $526.5,533.3,560.7,526.8,544.3$, and $548.5 \mathrm{~g} / \mathrm{m}^{2}$ in 2010 , increasing by $8.7,9.2,0.2,4.3,8.4$, and $11.3 \%$, respectively. Mean annual unit NPP values in farmland of single-cropping systems that fall into no obvious, slight, moderate, high, very high, and severe soil erosion classes were 397.3, 455.7, 476.5, 458.1, 479.4 , and $489.5 \mathrm{~g} / \mathrm{m}^{2}$ in 2000 , respectively, and correspondingly increased to $477.5,502.7,541.6,514.4,522.6$, and $526.4 \mathrm{~g} / \mathrm{m}^{2}$, increasing by $20.2,10.3,13.7,12.3,9.0$, and $7.5 \%$, respectively.

However, urbanization and soil erosion decreased farmland area, and farmland area converted between double- and singlecropping systems still led to an NPP decrease from 2000 to 2010 (Table 9). Annual NPP was $6.38 \times 10^{12}$ in 2000 , and decreased to $6.36 \times 10^{12} \mathrm{~g}$ in 2010 , decreasing by $0.2 \%$. The $0.2 \%$ decrease in NPP

Table 7

Changes of cropping system area due to soil erosion.

\begin{tabular}{|c|c|c|c|c|c|c|c|}
\hline Cropping system & & No obvious (0) & Slight $(0-5)$ & Moderate (5-25) & High (25-50) & Very high $(50-80)$ & Severe $(80-150)$ \\
\hline \multirow[t]{3}{*}{ Double } & 2000 (ha) & 59778 & 360886 & 144552 & 11123 & 687 & 3 \\
\hline & 2010 (ha) & 47164 & 375563 & 83462 & 5997 & 273 & 2 \\
\hline & Change (\%) & -21.1 & 4.1 & -42.3 & -46.1 & -60.3 & -33.3 \\
\hline \multirow[t]{3}{*}{ Single } & 2000 (ha) & 85009 & 312255 & 300457 & 75205 & 8002 & 215 \\
\hline & 2010 (ha) & 60800 & 235904 & 342243 & 64662 & 6647 & 134 \\
\hline & Change (\%) & -28.5 & -24.5 & 13.9 & -14.0 & -16.9 & -37.7 \\
\hline
\end{tabular}

Note: minus means decrease; Soil erosion unit: tha $^{-1}$ year $^{-1}$. 

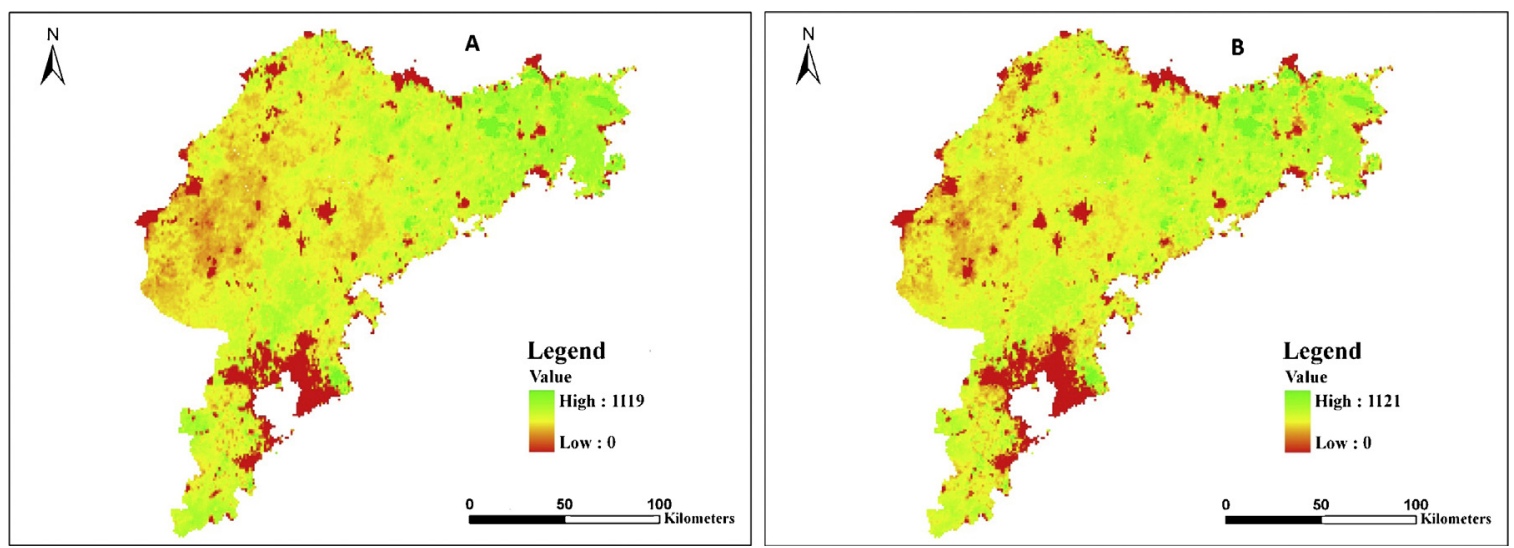

Fig. 5. Annual NPP in Shandong Peninsula (A, 2000; B, 2010; g/m²).

Table 8

Unit production of NPP in various soil erosion classes in 2000 and 2010.

\begin{tabular}{|c|c|c|c|c|c|c|c|}
\hline & & No obvious (0) & Slight $(0-5)$ & Moderate (5-25) & High (25-50) & Very high $(50-80)$ & Severe (80-150) \\
\hline \multirow[t]{3}{*}{ Double } & $2000\left(\mathrm{~g} / \mathrm{m}^{2}\right)$ & 484.4 & 488.3 & 559.4 & 505.2 & 502.3 & 492.7 \\
\hline & $2010\left(\mathrm{~g} / \mathrm{m}^{2}\right)$ & 526.5 & 533.3 & 560.7 & 526.8 & 544.3 & 548.5 \\
\hline & Change (\%) & 8.7 & 9.2 & 0.2 & 4.3 & 8.4 & 11.3 \\
\hline \multirow[t]{3}{*}{ Single } & $2000\left(\mathrm{~g} / \mathrm{m}^{2}\right)$ & 397.3 & 455.7 & 476.5 & 458.1 & 479.4 & 489.5 \\
\hline & $2010\left(\mathrm{~g} / \mathrm{m}^{2}\right)$ & 477.5 & 502.7 & 541.6 & 514.4 & 522.6 & 526.4 \\
\hline & Change (\%) & 20.2 & 10.3 & 13.7 & 12.3 & 9.0 & 7.5 \\
\hline
\end{tabular}

Soil erosion unit: tha $^{-1}$ year $^{-1}$.

Table 9

NPP in cropping systems in 2000 and 2010.

\begin{tabular}{|c|c|c|c|c|c|}
\hline & \multirow{2}{*}{$\begin{array}{l}\text { Double cropping system } \\
\text { Sum (g) }\end{array}$} & \multirow{2}{*}{$\begin{array}{l}\text { Single cropping system } \\
\text { Sum }(\mathrm{g})\end{array}$} & \multicolumn{3}{|l|}{ Total } \\
\hline & & & Mean $\left(\mathrm{g} / \mathrm{m}^{2}\right)$ & Sum (g) & Mean $\left(\mathrm{g} / \mathrm{m}^{2}\right)$ \\
\hline 2000 & $2.88 \times 10^{12}$ & $3.51 \times 10^{12}$ & 469.8 & $6.38 \times 10^{12}$ & 469.81 \\
\hline 2010 & $2.73 \times 10^{12}$ & $3.64 \times 10^{12}$ & 520.6 & $6.37 \times 10^{12}$ & 520.65 \\
\hline Change (\%) & & & 10.8 & -0.2 & 10.8 \\
\hline
\end{tabular}

Note: minus means decrease.

indicates that the increased unit NPP could not offset the combined effects of farmland decrease and adaptation on NPP.

\section{Discussion}

\subsection{The role of urbanization in reducing the soil erosion rate}

Analysing the relationships among soil erosion, area changes of cropping systems, and urbanization on the Shandong Peninsula, we discovered that urbanization has caused rural labor to decrease, leading to diminished areas of cropping systems in lands that have higher soil erosion rates, which has increased forest areas. This indicates that urbanization has the same role in returning farmland as the Grain-for-Green project. This will help to reduce the soil erosion rate on the Shandong Peninsula. The urbanization level is very high in eastern China, and to reduce the government budget, China's central government should not expand the Grain-for-Green project to eastern China.

\subsection{Factors that affect extraction of the double-cropping system}

The extraction of cropping systems was mainly dependent upon the vegetation type and its growing condition when the image was acquired. Single-cropping systems have a long fallow period before early May. Images acquired in this period could be easily obtained, and single-cropping systems could be easily extracted with higher accuracy according to this condition.

However, the double-cropping system only has two very short fallow periods. One fallow period is in late June when winter wheat is harvested and corn is not yet planted. This period is only 10 days long and rainfall often occurs. Images acquired in this period are very difficult to acquire. Therefore, double cropping could not be extracted according to this condition. Another fallow period is late October to early November when corn and other crops are harvested and winter wheat is not yet planted. This period is relatively long and lasts about 20 days, and double-cropping systems could be extracted according to this condition. However, the harvest date of corn and other crops is not regular, and some do not even harvest during this period, which would affect the accuracy of the double-cropping system data.

\subsection{NPP calculation}

Water stress index is a very important factor in calculating the NPP. Many factors could affect the water stress index, such as precipitation, evapotranspiration, and irrigation. In general, double-cropping systems were more highly affected by irrigation than the single-cropping system. However, irrigation data are not 
presently available at larger scales, and only precipitation and evapotranspiration are used to calculate the water stress index in this research. Therefore, this would greatly influence the calculated results of the double-cropping system NPP. In the future, methods for estimating irrigation areas should be explored by combining precipitation, evapotranspiration, and other factors.

\section{Conclusions}

Using spatial and statistical analysis, we determined that the rapid urbanization from 2000 to 2010 caused the area of urban and barren land to increase by $57.5 \%$, but also caused the area of singleand double-cropping systems in the land exposed to higher soil erosion rates to decrease. Meanwhile, some of the single-cropping system lands with slopes below $5^{\circ}$ that fall into the slight soil erosion class were converted to the double-cropping system to increase profits. Although the mean annual unit NPP tended to increase by $10.8 \%$ because of changes in climate, species, and management, decreasing the area of cropping systems still caused the total NPP to trend lower.

\section{Acknowledgments}

This work was supported by Key Research Program of the Chinese Academy of Sciences (KZZD-EW-14), National Science and Technology Support Program (2014FY210600), National Natural Science Foundation of China (41171334 and 41301596), Talent Fund of Yantai Institute of Coastal Zone Research, Ecological Innovation \& Breeding Project (Y254021031, Y355031061), the Science and Technology Project of Yantai (2012132), and USDA NIFA Project (2010-34263-21075). At last, thanks the anonymous reviewers for their helpful comments.

\section{References}

Allen, R.G., Pereira, L.S., Raes, D., Smith, M., 1998. Crop Evapotranspiration Guidelines for Computing Crop Water Requirements - FAO Irrigation and Drainage Paper 56. FAO, Rome.

Bechmann, M., Stålnacke, P., Kværnø, S., Eggestad, H.O., Øygarden, L., 2009. Integrated tool for risk assessment in agricultural management of soil erosion and losses of phosphorus and nitrogen. Sci. Total Environ. 407 (2), 749-759.

Dai, S.B., Lu, X.X., 2014. Sediment load change in the Yangtze River (Changjiang): a review. Geomorphology 215, 60-73.

Field, C.B., Randerson, J.T., Malmstrom, C.M., 1995. Global net primary production: combining ecology and remote sensing. Remote Sens. Environ. 51, 74-88.

Folland, C.K., Karl, T.R., Christy, J.R., Clarke, R.A., Gruza, G.V., Jouzel, J., Mann, M.E., Oerlemans, J., Salinger, M.J., Wang, S.W., 2001. Observed climate variability and change. Climate Change 2001: The Scientific Basis. Contribution of Working Group I to the Third Assessment Report of the Intergovernmental Panel on Climate Change. Cambridge University Press, Cambridge, United Kingdom and New York.

Hua, L., Zhang, Z.G., Feng, Y., Zhao, H., Li, J.B., Wang, X.R., Zhu, F.Y., 2006. Soil erosion and losses of nitrogen and phosphorus by using ${ }^{137} \mathrm{Cs}$ tracer in the areas around Miyun reservoir. Trans. Chin. Soc. Agric. Eng. 22 (1), 73-78.
Jiao, J.Y., Wang, Z.J., Zhao, G.J., Wang, W.Z., Mu, X.M., 2014. Changes in sediment discharge in the sediment-rich region of the Yellow River from 1955 to 2010: implications for further soil erosion control. J. Arid Land 2014, 1-10.

Liu, J.P., Xu, K.H., Li, A.C., Milliman, J.D., Velozzi, D.M., Xiao, S.B., Yang, Z.S., 2007. Flux and fate of Yangtze River sediment delivered to the East China Sea. Geomorphology 85 (3-4), 08-224.

Liu, B.Y., Bi, X.G., Fu, S.H., et al., 2010. Beijing Soil Loss Formula. Science Press, Beijing (in Chinese).

Local statistic Bureau, 2010. Local Statistic Yearbook. China Statistic Press, Beijing.

Lu, Q., Liang, F., Bi, X., Duffy, R., Zhao, Z.P., 2011. Effects of urbanization and industrialization on agricultural land use in Shandong Peninsula. Ecol. Indic. 11, 1710-1714.

Lu, Q., Xu, B., Liang, F., Gao, Z., Ning, J.C., 2013. Influences of the grain-for-green project on grain security in southern China. Ecol. Indic. 34, 616-622.

McCool, D.K., Foster, G.R., Renard, K.G., Yoder, D.C., Weesies, G.A., 1987. The Revised Universal Soil Loss Equation. Department of Defense/Interagency Workshop on Technologies to Address Soil Erosion on Department of Defense Lands, San Antonio, TX.

Otero, J.D., Figueroa, A., Munoz, F.A., Pena, M.R., 2011. Loss of soil and nutrients by surface runoff in two agro-ecosystems within an Andean paramo area. Ecol. Eng. 37, 2035-2043.

Potter, C.S., Randerson, J.T., Field, C.B., Matson, P.A., Vitousek, P.M., Mooney, H.A., Klooster, S.A., 1993. Terrestrial ecosystem production: a process model based on global satellite and surface data. Global Biogeochem. Cycles 7 (4), 811-841.

Pu, P.M., Cai, S.M., Zhu, H.H., et al., 1994. Project of Three Gorges Reservoir and Lakes in Middle and Low Reaches of Yangtz River. Science Press, Beijing (in Chinese).

Qi, X., Wang, K., Zhang, C., 2013. Effectiveness of ecological restoration projects in karst region of southwest China assessed using vegetation succession mapping. Ecol. Eng. 54, 245-253.

Quinton, J.N., Govers, G., Van Oost, K., Bardgett, R.D., 2010. The impact of agricultural soil erosion on biogeochemical cycling. Nat. Geosci. 3 (5), 311-314.

Remortel, V.R., Hamilton, M., Hickey, R., 2001. Estimating the LS factor for RUSLE through iterative slope length processing of DEM elevation data. Cartography 30 (1), 27-35.

Renard, K.G., Foser, G.R., Weesies, G.A., et al., 1997. Predicting Soil Erosion by Water: A Guide to Conservation Planning with the Revised Universal Soil Loss Equation (RUSLE). Agriculture Handbook No. 703. U. S. Department of Agriculture, Washington, D.C.

State Statistical Bureau, 2011. China Statistical Yearbook. China Statistics Press, Beijing.

Su, Z., Zhang, J., Nie, X., 2010. Effect of soil erosion on soil properties and crop yields on slopes in the Sichuan Basin, China. Pedosphere 20 (6), 736-746.

Wischmeier, W.H., Smith, D.D., 1978. Predicting Rainfall Erosion Losses: A Guide to Conservation Planning. Agriculture Handbook No. 537. U. S. Department of Agriculture.

Wu, X., Li, Z., Fu, B., Zhou, W., Liu, H., Liu, G., 2014. Restoration of ecosystem carbon and nitrogen storage and microbial biomass after grazing exclusion in semi-arid grasslands of Inner Mongolia. Ecol. Eng. 73, 395-403.

Xie, Y., Liu, B.Y., Zhang, W.B., 2000. Study on standard of erosive rainfall. J. Soil Water Conserv. 14 (4), 6-11 (in Chinese with English abstract).

Xu, Y.Q., Luo, D., Peng, J., 2011. Land use change and soil erosion in the Maotiao River watershed of Guizhou Province. J. Geogr. Sci. 21 (6), 1138-1152.

Yang, S.L., Belkin, I.M., Belkina, A.I., Zhao, Q.Y., Zhu, J.P., Ding, X., 2003. Delta response to decline in the sediment supply from the Yangtze River: evidence of the recent four decades and expectations for the next half-century. Estuar. Coast. Shelf Sci. 57, 689-699.

Yue, X., Mu, X., Zhao, G., Shao, H., Gao, P., 2014. Dynamic changes of sediment load in the middle reaches of the Yellow River basin, China and implications for ecorestoration. Ecol. Eng. 73, 64-72.

Zhang, Z.B., Duan, Z.Y., 2009. Where is the way for increasing the ability of grain security in China. Bull. Chin. Acad. Sci. 2009 (6), 610-616 (in Chinese with English abstract).

Zhang, W.B., Xie, Y., Liu, B.Y., 2002. Rainfall erosivity estimation using daily rainfall amounts. Sci. Geogr. Sin. 22 (6), 705-711 (in Chinese with English abstract). 